\title{
Effect of elaboration levels on content comprehension
}

\author{
JEFFREY S. KIXMILLER, DANIEL L. WANN, CATHY A. GROVER, and STEPHEN F. DAVIS \\ Emporia State University, Emporia, Kansas
}

\begin{abstract}
In this experiment we investigated the effect(s) on content comprehension of studying using different levels of elaborative rehearsals. The elaborative methods examined involved studying an article and then preparing and giving a 3- to 4-min presentation from either the first-person or the third-person perspective. A third (control) condition involved study only. A 17-item multiplechoice test was given during the following class period to assess the subjects' content comprehension for the article. The same test was readministered 2 weeks later to assess long-term content comprehension. Analysis of variance yielded significance for the groups factor for both test administrations. Specific contrast effects indicated that both the first- and third-person conditions produced significantly better content comprehension on the original testing occasion, whereas the third-person condition produced significantly greater content comprehension on the second testing occasion.
\end{abstract}

Research that has investigated different levels of cognitive processing has demonstrated that elaborative rehearsal is a more effective means of encoding information than is simple maintenance rehearsal (Craik \& Lockhart, 1972; Craik \& Tulving, 1975; Craik \& Watkins, 1973). More specifically, elaborative rehearsal purportedly leads to deeper levels of processing and better memory storage, whereas maintenance rehearsal is simply a repetitive process designed to maintain an item's availability in memory. However, in applying these findings to the classroom setting, it is important to consider the elaborative styles being employed. Older (1979), for example, discussed specific elaborative techniques used in an introductory psychology course. He contended that subject matter that is personally meaningful to students will enhance learning. Furthermore, Older suggested that experience is the most effective strategy for students to meaningfully incorporate new information. This view is in agreement with the views of Ausubel (1968) and Bruner (1961), who suggested that by organizing and structuring information in a meaningful manner, students can facilitate their understanding of that material.

In view of the above-mentioned reports, the present investigation sought to examine the effect(s) that studying under different levels of elaboration would have upon content comprehension. More specifically, it was hypothesized that students who processed information at a high elaborative level would display higher scores subsequently on an objective test than would subjects who processed the same information at a lower elaborative level. Also, differences attributable to first- versus third-person elaboration were investigated.

Requests for reprints may be addressed to any of the authors at the Department of Fsychology, Emporia State University, Emporia, KS 66801-5087.

\section{METHOD}

\section{Subjects}

Forty-two college students ( 21 males, 21 females) volunteered to serve as subjects. All students were enrolled in an introductory psychology class at the time of the experiment.

\section{Stimuli and Apparatus}

The materials employed in this study consisted of an article on interpersonal proximity (Rosenfeld, 1965) and a 17-item objective (multiplechoice) test designed to test the subject's knowledge of the article. ${ }^{1}$ The manuscript was edited slightly so that it would be more easily understood by freshman- and sophomore-level students.

\section{Procedure}

The subjects were randomly assigned to one of three groups: study only (SO), third-person elaboration (3P), or first-person elaboration (1P). The only restriction applied to the randomization process was that an equal number of males and females appear in each group. Following completion of the designated class period, each subject was individually given the article and instructions appropriate to his/her assigned group. The subjects in Group SO were told simply to study the article, whereas those in Group 3P were instructed that they were to prepare a 3- to 4-min presentation about the article, using the third person. The subjects in Group 1P were instructed to prepare a 3- to 4-min presentation about the article from the first-person perspective of the author. All subjects were instructed that they would be tested over the article's content at the next regular class meeting (i.e., in 2 days).

On the test day, all subjects initially met in the regular classroom. The subjects then were sent individually to a second room and were asked to make the 3- to 4-min presentation. A small group of graduatestudent volunteers $(n=5)$ were present in the second room. The SO subjects were asked to make a 3- to 4-min impromptu presentation about their summer vacation. This procedure was designed to serve as a control for the presentation time expended by the two elaboration groups. Upon completion of the presentation, each subject was directed to a third room, in which the multiple-choice test was administered. When the test was completed, the subjects returned to the original classroom, where they were debriefed concerning the rationale of the study and were assured that scores on the test would not affect their course grade. Exactly 2 weeks following the testing session, the test was administered again during a regular class session. 


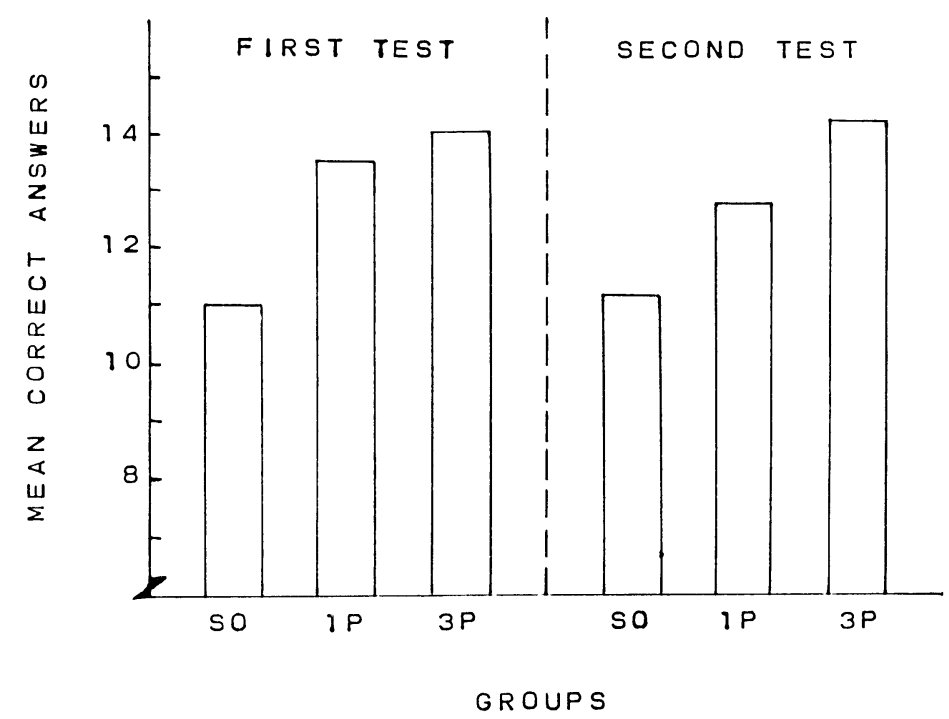

Figure 1. Group mean correct answers for the study only (SO), first-person elaboration (1P), and third-person elaboration (3P) groups for the initial testing session (left panel) and second testing session (right panel).

\section{RESULTS}

Group mean correct answers for the two testing sessions are shown in Figure 1. As can be seen, at both testing sessions the elaboration subjects (Groups 3P and 1P) displayed higher scores than did Group SO subjects.

In support of the graphical impression created by Figure 1, analyses of variance yielded significance for the groups effect for both the initial $[F(2,39)=3.37, p=$ $.043]$ and second $[F(2,39)=3.66, p=.034]$ testing sessions. Subsequent Newman-Keuls tests indicated that the scores of both elaboration groups were significantly $(p<.05)$ higher than the scores of the SO subjects on the initial testing occasion. However, only the difference between Group 3P and Group SO achieved significance $(p<.05)$ at the second testing session.

\section{DISCUSSION}

It is apparent that the level of elaborative incorporation of content had a significant influence upon subsequent comprehension. Those students who used an elaborative studying technique-that is, development of a first- or third-person presentation-showed significant initial test results compared with students who employed the SO techniquè. Moreover, it was found that significant gains (in terms of test performance) were retained over a 2 -week period by the $3 P$ subjects.

The discussion of three major implications seems appropriate. First, the present results suggest the advisability of incorporating presentations into the teacher's catalog of regular classroom activities. In this regard it should be noted that in some classroom situations (Gorman, Law, \& Lindegren, 1981; Klugh, 1983), presentations already are being utilized effectively. Second, preparing to make a presentation is suggested as an alternate method to supplement the traditional reading/outlining mode of studying. Third, students who are taught/encouraged to present information also are acquiring a very valuable skill. As McGovern and Ellett (1980) suggested, "the translation of one's educational experiences into specific, behaviorally concrete skills is crucial"' (p. 237).
Finally, the present data suggest fruitful avenues for future research. An evaluation of comprehension retention over longer periods of time, such as a month or an academic semester, is clearly needed. Second, the inability of the $1 \mathrm{P}$ subjects to retain superior comprehension over the 2-week period deserves attention. Why there was a difference between the two elaboration groups at the second testing period is not clear.

\section{REFERENCES}

Ausubel, F. P. (1968). Educational psychology: A cognitive view. New York: Holt, Rinehart \& Winston.

Bruner, J. S. (1961). The process of education. Cambridge, MA: Harvard University Press.

CRAIK, F. I., \& LockHART, R. S. (1972). Levels of processing: A framework for memory research. Journal of Verbal Learning \& Verbal Behavior, 11, 671-684.

Craik, F. I., \& Tulving, E. (1975). Depth of processing and the retention of words in episodic memory. Journal of Experimental Psychology, 104, 268-294.

Craik, F. I., \& WATKINS, M. J. (1973). The role of rehearsal in shortterm memory. Journal of Verbal Learning \& Verbal Behavior, 12, 599-607.

Gor' IAN, M. E., LAW, A., \& Lindegren, T. (1981). Making students tak' a stand: Active learning in introductory psychology. Teaching of Psychology, 8, 164-166.

KLUGH, H. E. (1983). Writing and speaking skills can be taught in psychology classes. Teaching of Psychology, 10, 170-171.

McGovern, T. V., \& ElletT, S. E. (1980). Bridging the gap: Psychology classroom to the marketplace. Teaching of Psychology, 7, 237-238.

OLDER, J. (1979). Improving the introductory psychology course. Teaching of Psychology, 6, 75-77.

RoSENFELD, H. M. (1965). Effect of an approval-seeking induction on interpersonal proximity. Psychological Reports, 17, 120-122.

\section{NOTE}

1. Copies of the edited article and multiple-choice test employed in this experiment are available upon request.

(Manuscript received for publication July 6, 1987.) 